\title{
Breastfeeding in Cystic Fibrosis: A Systematic Review on Prevalence and Potential Benefits
}

\author{
Carla Colombo ${ }^{1,2, *(\mathbb{D}}$, Gianfranco Alicandro ${ }^{1,2}{ }^{(0}$, Valeria Daccò ${ }^{1}$, Alessandra Consales ${ }^{3,4}$, Fabio Mosca ${ }^{3,4}$, \\ Carlo Agostoni ${ }^{4,5}\left(\mathbb{D}\right.$ and Maria Lorella Giannì ${ }^{3,4}$
}

1 Fondazione IRCCS Ca' Granda Ospedale Maggiore Policlinico, Cystic Fibrosis Center, 20122 Milan, Italy; gianfranco.alicandro@unimi.it (G.A.); valeria.dacco@policlinico.mi.it (V.D.)

2 Department of Pathophysiology and Transplantation, Università degli Studi di Milano, 20122 Milan, Italy

3 Fondazione IRCCS Ca' Granda Ospedale Maggiore Policlinico, NICU, 20122 Milan, Italy; alessandra.consales@unimi.it (A.C.); fabio.mosca@unimi.it (F.M.); maria.gianni@unimi.it (M.L.G.)

4 Department of Clinical Sciences and Community Health, Università degli Studi di Milano, 20122 Milan, Italy; carlo.agostoni@unimi.it

5 Fondazione IRCCS Ca' Granda Ospedale Maggiore Policlinico, Pediatric Unit, 20122 Milan, Italy

* Correspondence: carla.colombo@unimi.it; Tel.: +39-0255032456

Citation: Colombo, C.; Alicandro, G.; Daccò, V.; Consales, A.; Mosca, F.; Agostoni, C.; Giannì, M.L.

Breastfeeding in Cystic Fibrosis: A Systematic Review on Prevalence and Potential Benefits. Nutrients 2021, 13, 3263. https://doi.org/10.3390/ nu13093263

Academic Editor: Margarita Pérez

Received: 14 July 2021

Accepted: 14 September 2021

Published: 18 September 2021

Publisher's Note: MDPI stays neutral with regard to jurisdictional claims in published maps and institutional affiliations.

Copyright: (c) 2021 by the authors. Licensee MDPI, Basel, Switzerland. This article is an open access article distributed under the terms and conditions of the Creative Commons Attribution (CC BY) license (https:// creativecommons.org/licenses/by/ $4.0 /)$.
Abstract: Breastfeeding (BF) is considered the normative standard of feeding for all infants. However, the impact of BF in patients with cystic fibrosis (CF) is not completely defined. Therefore, we conducted a systematic review to evaluate BF prevalence in the CF population and its impact on anthropometric and pulmonary outcomes. We searched MEDLINE, Embase and the Cochrane Library for original articles published in English up to 4 December 2020 that report the prevalence of BF and/or any measure of association between BF and anthropometric or pulmonary outcomes. Nine observational studies were identified (six retrospective cohort studies, one prospective cohort study, one survey and one case-control study within a retrospective cohort). The BF rate in CF patients is lower than that of the healthy population (approximately 50-60\% of infants were breastfed at any time). The benefits in anthropometric outcomes of BF for $>2$ months in this at-risk population are unclear. A few relatively small studies suggest a potential benefit of BF in reducing lung infections, although data are inconsistent. The currently available data are insufficient to draw definite conclusions on the benefits of exclusive BF in anthropometric and pulmonary outcomes in CF. Clinical trials evaluating well-defined BF promotion interventions are needed.

Keywords: cystic fibrosis; breastfeeding; infant feeding; growth; infections; pulmonary outcomes

\section{Introduction}

Cystic fibrosis (CF) is a life-shortening autosomal recessive genetic condition affecting more than 90,000 people worldwide [1]. It is caused by mutations in the CF transmembrane conductance regulator (CFTR) gene, which alters the physiological sodium and chloride transport, resulting in viscous secretions. CF is a multisystem disease affecting the respiratory, gastrointestinal and reproductive tracts, and the sweat glands.

For many years, breastfeeding (BF) for infants with CF was discouraged, mainly due to concerns regarding reports of hypoproteinemia, hyponatremia and vitamin D and E deficiency. Due to the associated limitations in the absorption of fats and fat-soluble vitamins, BF was considered inadequate, in terms of energy supply, protein and sodium content, to meet the increased requirements of infants with $\mathrm{CF}$, particularly for those with pancreatic insufficiency (PI) and meconium ileus (MI) [2,3]. However, these events are unlikely to be related to BF per se and, in the modern era of CF nutritional care, can be easily prevented with close monitoring of nutritional status, adequate sodium and vitamin supplementation, and pancreatic enzyme replacement therapy (PERT).

Starting from the 1990s, the increasing evidence of several benefits of BF in healthy infants led to a change in perspective, with $77 \%$ of $\mathrm{CF}$ centers recommending BF alone 
or in any combination with hydrolyzed formula and PERT, if required. However, it was only in 2002 that the CF Foundation Consensus approved BF as the recommended primary source of nutrition in the first year of life for patients with CF [4]. Accordingly, the 2016 ESPEN-ESPGHAN-ECFS guidelines [5] recommended exclusive BF for newly diagnosed infants with $\mathrm{CF}$, highlighting the need for specific advice regarding PERT, salt supplements and nutritional intake. However, the optimal duration of exclusive BF was not indicated, leaving the WHO general recommendations [6] as the main indication.

Therefore, collecting evidence on the potential benefits of BF for infants with CF would be important to give evidence-based recommendations to parents in order to provide infants with CF with the best nutritional support from early life.

To this aim, we conducted a systematic review on BF prevalence in CF and its relationship with anthropometric and pulmonary outcomes.

\section{Materials and Methods}

We searched MEDLINE, Embase and the Cochrane Library databases for original articles published in English up to 4 December 2020 that report the prevalence of BF and/or any measure of association between BF and anthropometric or pulmonary outcomes. Citations were exported from the databases and then imported to Rayyan for title and abstract screening [7]. Weight, length/height and BMI (expressed as raw values or z-scores for age and sex), as well as weight-for-length z-scores, were considered as anthropometric outcomes, while the number of pulmonary exacerbations, IV antibiotic treatments, hospitalizations, lung infections, radiological scores of lung disease and forced expiratory volume in one second $\left(\mathrm{FEV}_{1}\right)$ were considered among pulmonary outcomes.

We included articles reporting randomized clinical trials and observational studies, while reviews, opinion papers, conference proceedings and studies where the analysis was not based on individual data were excluded. The following search terms were used for the search: "cystic fibrosis" AND ("breastfeeding" OR "breastfed"). Titles and abstracts were screened, and the full texts of the eligible articles were obtained. The references included in the full text of the eligible articles were manually searched for studies that could have been missed.

From the included articles, we extracted the following data: year of publication, country where the study was conducted, study design, number of enrolled patients, prevalence and duration of $\mathrm{BF}$, groups compared, measured outcomes and corresponding results.

Since we did not find any randomized clinical trial related to the objectives of our systematic review, we used the Newcastle-Ottawa Scale to assess the risk of bias in each cohort or case-control study [8]. The risk of bias for studies reporting results from surveys was evaluated trough the response rate.

The study findings were reported according to the Preferred Reporting Items for Systematic Reviews and Meta-Analyses (PRISMA) guidelines [9].

\section{Results}

\subsection{Selected Articles}

Figure 1 shows the flow diagram of the studies included in this review.

The systematic search yielded 199 unique items; 39 were considered eligible after screening of the title and abstract. Thirty-two publications were excluded: 29 were published as conference proceedings, one article was an opinion paper [10], one article was a survey among CF center directors that did not report individual data [11] and one article [12] reported preintervention and postintervention values of growth parameters after a project to improve BF in CF, but it did not show a comparison between breastfed and formula-fed infants. Thus, seven studies were identified by the systematic search [13-19], and two studies were identified by the manual search $[20,21]$.

Table 1 gives a summary overview of the nine selected articles: six retrospective cohort studies, one prospective cohort study, one survey and one case-control study within a retrospective cohort. 


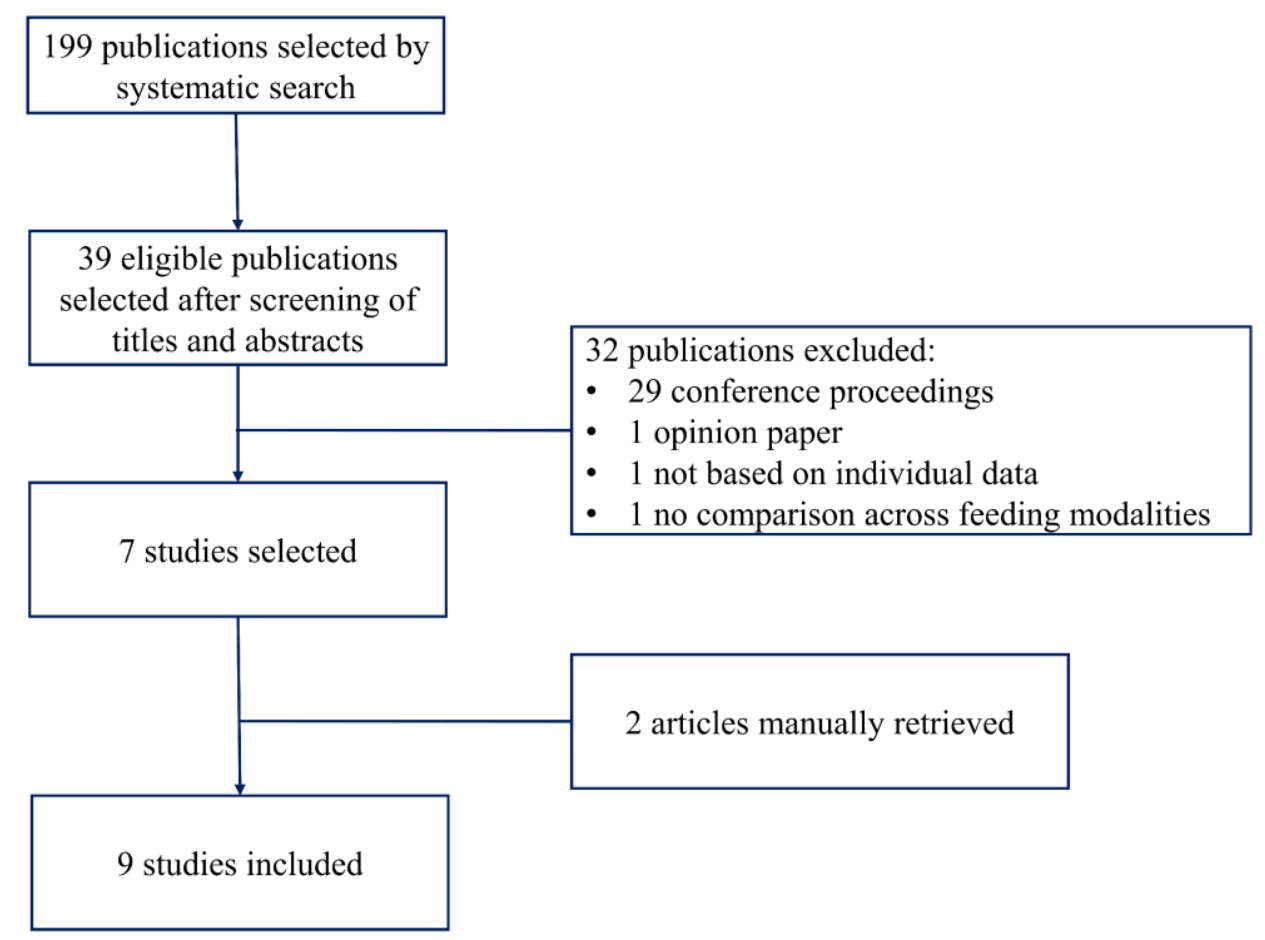

Figure 1. Flow diagram of the studies selection.

Table 1. Summary overview of the selected studies.

\begin{tabular}{|c|c|c|}
\hline $\begin{array}{l}\text { First Author (Year of Publication), } \\
\text { Country [Reference] }\end{array}$ & Study Design & Enrolled Patients \\
\hline Holliday et al. (1991), Australia [20] & Single-center retrospective cohort study & $\begin{array}{l}65 \mathrm{CF} \text { infants without MI and } 16 \text { infants } \\
\text { with MI }\end{array}$ \\
\hline Parker EM et al. (2004), USA [13] & Multicenter survey & 768 CF patients \\
\hline Colombo et al. (2007), Italy [14] & Single-center retrospective cohort study & $\begin{array}{l}146 \text { patients (aged } 5-18 \text { years) seen at the } \\
\text { CF center between September } 2003 \text { and } \\
\text { April } 2004\end{array}$ \\
\hline Jadin et al. (2011), USA [15] & Multicenter retrospective cohort study & $\begin{array}{l}103 \text { CF infants born between } 1994 \text { and } \\
2006 \text { who were diagnosed through NBS }\end{array}$ \\
\hline Rosenfeld et al. (2012), USA [16] & Multicenter retrospective cohort study & $\begin{array}{l}264 \mathrm{CF} \text { patients aged }<2 \text { years with no } \\
\text { isolation of } P \text {. aeruginosa from any } \\
\text { respiratory culture prior to enrollment }\end{array}$ \\
\hline Leung et al. (2017), USA [17] & Multicenter prospective cohort study & $\begin{array}{l}231 \text { CF infants younger than } 3.5 \text { months } \\
\text { diagnosed by NBS }\end{array}$ \\
\hline Munck et al. (2018), France [18] & Multicenter prospective cohort study & $\begin{array}{l}105 \text { infants with no history of MI } \\
\text { recruited between April } 2010 \text { and } \\
\text { September } 2011 \text { after the first visit for } \\
\text { confirmatory CF diagnosis after NBS }\end{array}$ \\
\hline Padoan et al. (2019), Italy [19] & $\begin{array}{l}\text { Multicenter case-control study within a } \\
\text { retrospective cohort study }\end{array}$ & $\begin{array}{l}85 \text { CF infants with MI born between } 2009 \\
\text { and } 2016 \text { and diagnosed by symptoms }\end{array}$ \\
\hline Fitzgerald et al. (2020), Ireland [21] & Multicenter retrospective cohort study & $\begin{array}{l}186 \text { CF infants ( } 77 \text { born between July } 2008 \\
\text { and June } 2011 \text { clinically diagnosed and } \\
109 \text { born between July } 2011 \text { and June } 2016 \\
\text { diagnosed through NBS) }\end{array}$ \\
\hline
\end{tabular}


The risk of bias for the cohort and case-control studies was generally low, although some comparability issues emerged (Table 2). In fact, the majority of the studies contained no or only partial control for important confounders, including PI, MI and socioeconomic status. With regard to the only survey [13] included in this systematic review, the response rate was very low $(27 \%)$, with only 868 questionnaires returned out of 3200 sent, leaving doubts about the representativeness of the survey population.

Table 2. Risk of bias for the included case-control and cohort studies according to the Newcastle-Ottawa scale.

\begin{tabular}{|c|c|c|c|c|c|c|}
\hline $\begin{array}{c}\text { First Author (Year of } \\
\text { Publication) [Reference] }\end{array}$ & Study Design & Selection & Comparability & Exposure $^{a}$ & Outcome $^{a}$ & $\begin{array}{c}\text { Score } \\
\text { (Maximum: 9) }\end{array}$ \\
\hline Holliday et al. (1991) [20] & Cohort & 4 & 0 & NA & 3 & 7 \\
\hline Colombo et al. (2007) [14] & Cohort & 4 & 2 & NA & 3 & 9 \\
\hline Jadin et al. (2011) [15] & Cohort & 4 & 1 & NA & 3 & 8 \\
\hline Rosenfeld et al. (2012) [16] & Cohort & 4 & 0 & NA & 3 & 7 \\
\hline Leung et al. (2017) [17] & Cohort & 4 & 0 & NA & 3 & 7 \\
\hline Munck et al. (2018) [18] & Cohort & 4 & 1 & NA & 3 & 8 \\
\hline Padoan et al. (2019) [19] & $\begin{array}{c}\text { Case/control } \\
\text { within a cohort }\end{array}$ & 4 & 0 & 3 & NA & 7 \\
\hline Fitzgerald et al. (2020) [21] & Cohort & 4 & 2 & NA & 3 & 9 \\
\hline
\end{tabular}

NA: not applicable. ${ }^{\text {a }}$ According to the Newcastle-Ottawa scale, points for exposure are scored only for case-control studies and points for outcome only for cohort studies. Higher scores indicate a lower risk of bias.

\subsection{Prevalence and Duration of Breastfeeding}

All nine identified studies reported the prevalence of BF in CF (Table 3).

Table 3. Summary overview of the studies reporting on prevalence of breastfeeding in cystic fibrosis.

\begin{tabular}{|c|c|}
\hline First Author (Year of Publication) [Reference] & Prevalence of Breastfeeding \\
\hline Holliday et al. (1991) [20] & $\begin{array}{l}\text { Patients without MI: } 63.1 \% \text { BF at least } 3 \mathrm{~m}, 46.2 \% \text { exBF. } \\
\text { Patients with MI: } 43.8 \% \text { BF at least } 3 \mathrm{~m} .\end{array}$ \\
\hline Parker EM et al. (2004) [13] & $49 \%$ BF at any time, $18 \%$ exBF. \\
\hline Colombo et al. (2007) [14] & $\begin{array}{l}62 \% \text { BF at any time, } 23 \% \mathrm{BF}>4 \mathrm{~m} \text {. } \\
\mathrm{BF} \text { rate at any time higher among PS patients }(74 \%) \text { than PI patients }(57 \%) \text {. }\end{array}$ \\
\hline Jadin et al. (2011) [15] & $\begin{array}{l}51 \% \mathrm{BF} \text { at any time }(26 \% \text { exBF }<1 \mathrm{~m}, 10.7 \% \text { ExBF }=1 \mathrm{~m} \text { and } 13.6 \% \text { exBF } \geq 2 \mathrm{~m}) \text {. } \\
\mathrm{BF} \text { rates at any time higher among PS patients }(66 \%) \text { than PI patients without } \\
\mathrm{MI}(48 \%) \text { and patients with MI }(54 \%) \text {. }\end{array}$ \\
\hline Rosenfeld et al. (2012) [16] & Ever BF: $52.3 \%$. \\
\hline Leung et al. (2017), USA [17] & $\mathrm{BF}$ at $3 \mathrm{~m}$ of age: $43.3 \%, 25 \%$ exBF. \\
\hline Munck et al. (2018) [18] & $\begin{array}{l}\text { At initial visit the rates of exclusively or partial BF were } 47 \% \text { among PI patients } \\
\text { and } 20 \% \text { among PS patients. } \\
\text { Corresponding figures at } 6 \mathrm{~m}: 20 \% \text { among PI patients and } 28 \% \text { among PS } \\
\text { patients. } \\
47.6 \% \text { of patients received exclusive BF during the first } 3 \mathrm{~m} \text { of life. }\end{array}$ \\
\hline Padoan et al. (2019) [19] & Ever BF in the first $3 \mathrm{~m}$ of life: $54 \%$. \\
\hline Fitzgerald et al. (2020) [21] & $\begin{array}{l}\text { Ever BF: } 51.4 \% \text { among the NBS group and } 54.2 \% \text { among the clinically } \\
\text { diagnosed group. }\end{array}$ \\
\hline
\end{tabular}

BF: breastfed; CF: cystic fibrosis; exBF: exclusively breastfed; MI: meconium ileus; NBS: newborn screening; PI: pancreatic insufficiency; PS: pancreatic sufficiency.

The prevalence of BF was approximately 50-60\%. The BF rate was found to be higher among patients with PS than among patients with PI and MI. Overall, BF prevalence was 
consistently lower compared to that of the general population, and this was also the case for exclusive BF rate. However, the figures provided by the included studies are difficult to compare since they were collected at different time points.

\subsection{Breastfeeding and Anthropometric Outcomes}

Six studies investigated the relationship between $\mathrm{BF}$ and anthropometric outcomes in CF (Table 4).

Table 4. Summary overview of the studies evaluating the association between breastfeeding and anthropometric outcomes in cystic fibrosis.

\begin{tabular}{|c|c|c|}
\hline $\begin{array}{l}\text { First Author (Year of } \\
\text { Publication) [Reference] }\end{array}$ & Comparisons & Length/Height \\
\hline Holliday et al. (1991) [20] & $\mathrm{BF} \geq 3 \mathrm{~m}$ vs. no $\mathrm{BF}$ or $\mathrm{BF}<3 \mathrm{~m}$ & $\begin{array}{l}\text { No significant differences in } \mathrm{Lz} \text { at } \\
\text { the age of } 3,6,12,18 \text { and } 24 \mathrm{~m} \\
\text { among infants without } \mathrm{MI} \text {. } \\
\text { In the subgroup of infants with } \mathrm{MI} \text {, } \\
\text { mean values of } \mathrm{Lz} \text { at the age of } 24 \mathrm{~m} \\
\text { were higher among infants } \mathrm{BF} \geq 3 \\
\mathrm{~m} \text { as compared to those not } \mathrm{BF} \text { or } \\
\mathrm{BF}<3 \mathrm{~m} \text { : } \\
\mathrm{Lz} \text { at } 24 \mathrm{~m}: 0.94 \mathrm{vs} .-0.85, p=0.01 \text {. }\end{array}$ \\
\hline
\end{tabular}

\begin{tabular}{ll}
\hline Parker EM et al. (2004) [13] & $\begin{array}{l}\text { noBF, BF supplemented with } \\
\text { formula }<6 \mathrm{~m}, \mathrm{BF} \text { supplemented } \\
\text { with formula } \geq 6 \mathrm{~m}, \text { exBF }<6 \mathrm{~m}, \\
\\
\text { exBF } \geq 6 \mathrm{~m}\end{array}$ \\
\hline Colombo et al. (2007) [14] & $\begin{array}{l}\text { BF }>4 \mathrm{~m} \text { vs. no BF or } 1-4 \mathrm{~m} \mathrm{BF} \text { (any } \\
\text { type of BF: exclusive, predominant, } \\
\text { partial) }\end{array}$
\end{tabular}

Not evaluated

Weight/BMI

No significant differences in $\mathrm{Wz}$ at

the age of $3,6,12,18$ and $24 \mathrm{~m}$

among infants without MI.

In the subgroup of infants with MI,

mean values of $\mathrm{Wz}$ at the age of 12

and $24 \mathrm{~m}$ were higher among

infants $\mathrm{BF} \geq 3 \mathrm{~m}$ as compared to those not $\mathrm{BF}$ or $\mathrm{BF}<3 \mathrm{~m}$ :

Wz at $12 \mathrm{~m}: 0.96$ vs. $-1.19, p=0.001$,

Wz at $24 \mathrm{~m}$ : 0.94 vs. $-0.85, p=0.007$.

No significant differences in BMI ( $p$ $=0.67$ )

No significant differences in Lz (at the time of enrollment and at 1 year of age).

Mean Lz values at 1 year of age were $-0.84,-1.03$ and -0.70 among no BF, BF $1-4 \mathrm{~m}$ and $\mathrm{BF}>4$ $\mathrm{m}$ infants, respectively $(p=0.47)$.

\section{Jadin et al. (2011) [15] exBF $<1 \mathrm{~m}, 1 \mathrm{~m}, \geq 2 \mathrm{~m}$ and} exclusive standard caloric density formula (exFF20, $20 \mathrm{kcal}$ per ounce) and high caloric density formula (exFF22, $22 \mathrm{kcal}$ per ounce)

$\begin{array}{ll}\text { Leung et al. (2017) [17] } & \begin{array}{l}\text { exBF at } 3 \mathrm{~m} \text { of age vs. exFF or Not evaluated } \\ \text { combination }\end{array}\end{array}$

No significant differences in Lz.

No significant differences in $\mathrm{Wz}$ (at the time of enrollment and at 1 year of age).

Mean $W z$ values at 1 year of age were $-0.51,-0.68$ and -0.44 among no BF, BF no BF, BF $1-4 \mathrm{~m}$ and BF > $4 \mathrm{~m}$ infants, respectively $(p=0.54)$.

Rapid decline in $\mathrm{Wz}$ from birth to 6 $m$ of age observed only in children with exBF $>2 \mathrm{~m}(p<0.0001)$.

$\mathrm{Wz}$ at $3 \mathrm{~m}$ of age higher among exBF infants as compared to exFF and those receiving a combination of FF and BF (mean difference: 0.54, $95 \%$ CI: 0.22 to 0.87$)$. However, no differences emerged when exBF infants were compared with exFF infants (mean difference at $3 \mathrm{~m}$ of age: $0.13,95 \% \mathrm{CI}:-0.17$ to 0.44 ). No significant differences at 6 and $12 \mathrm{~m}$ of age.

Munck et al. (2018) [18]

Different comparisons for nutritional outcomes (exBF vs. exFF during the first $3 \mathrm{~m}$ of life) and pulmonary outcomes (exclusively or partially BF for $3 \mathrm{~m}$ vs. exFF)

\section{No significant association between} exBF and $\mathrm{Lz} \geq 10$ th at the age of 2 years (OR: 0.66, 95\% CI: 0.22-1.96).
No significant association between exBF and $\mathrm{Wz} \geq 10$ th percentile $(\mathrm{OR}$ : 0.39, 95\% CI: 0.08-1.99).

BF: breastfed; BMI: body mass index; CF: cystic fibrosis; CI: confidence Intervals; exBF: exclusively breastfed; exFF: exclusively formula fed; exFF20: exclusive standard caloric density formula (20 kcal per ounce); exFF22: exclusive high caloric density formula (22 kcal per ounce); FF: formula fed; Lz: length-for-age z score; MI: meconium ileus; OR: odds ratio; Wz: weight-for-age z score.

The association between BF and anthropometric outcomes failed to reach statistical significance in the majority of the studies. The multi-center retrospective cohort study by Jadin et al. showed a rapid decline in weight-for-age z-scores from birth to six months of age only in children who had been exclusively breastfed for more than two months [15]. In contrast, Leung et al. found a positive association between exclusive BF and weight-for-age 
z-scores at 3 months of age, but this result was not confirmed at 6 and 12 months of age [17]. A positive association between BF and weight-for-age z-scores at 12 and 24 months of age was also found in a small subgroup $(\mathrm{N}=16)$ of patients with MI [20].

\subsection{Breastfeeding and Pulmonary Outcomes}

Seven studies investigated the relationship between BF and pulmonary outcomes in CF (Table 5).

Table 5. Summary overview of the studies evaluating the association between breastfeeding and pulmonary outcomes in cystic fibrosis.

\begin{tabular}{lll}
\hline $\begin{array}{l}\text { First Author (Year of } \\
\text { Publication) [Reference] }\end{array}$ & Comparisons & Respiratory Function \\
\hline Parker EM et al. (2004) [13] & $\begin{array}{l}\text { noBF, BF supplemented with } \\
\text { formula }<6 \mathrm{~m}, \mathrm{BF} \text { supplemented } \\
\text { with formula } \geq 6 \mathrm{~m}, \mathrm{exBF}<6 \mathrm{~m}, \\
\text { exBF } \geq 6 \mathrm{~m}\end{array}$ & $\begin{array}{l}\text { No significant differences in } \\
\mathrm{FEV}_{1} \% \text { collected at the time of } \\
\text { filling out the survey questionnaire } \\
(p=0.42) .\end{array}$ \\
& $\begin{array}{l}\text { FEV1 values were } \leq 70 \%, 71-90 \% \\
\text { and }>90 \% \text { in } 20,33 \text { and } 47 \% \text { of } \\
\text { patients who were not } \mathrm{BF} \text { as }\end{array}$ \\
& $\begin{array}{l}\text { compared to } 16,31 \text { and } 55 \% \text { of } \\
\text { patients who were exBF } \geq 6 \mathrm{~m} .\end{array}$
\end{tabular}

Lung Infections and Other Pulmonary Outcomes

Percentages of patients who received $0-1,2-3, \geq 4$ courses of IV antibiotics over the 2 years prior to the enrolment were 72,16 and $12 \%$ among no BF and 84,10 and $6 \%$ among those exBF $\geq 6 \mathrm{~m}$ $(p=0.03)$.

No significant differences in age at onset of symptoms ( $p=0.28$ ): $64,75,82$ and $90 \%$ of patients who were not BF had symptoms onset by 3, 6, 12 and $24 \mathrm{~m}$, respectively, as compared to $60,72,79$ and $87 \%$ among patients who were exBF $\geq 6 \mathrm{~m}$.

Colombo et al. (2007) [14] $\quad$ BF $>4 \mathrm{~m}$ vs. no BF or 1-4 m BF (any type of BF: exclusive, predominant, or partial)
Mean $\mathrm{FEV}_{1} \%$ values at the time of enrollment were 91,98 and 112 among no $\mathrm{BF}, \mathrm{BF} 1-4 \mathrm{~m}$ and $\mathrm{BF}>4$ $\mathrm{m}$ infants, respectively $(p<0.001)$. Mean FVC\% values at the time of enrollment were 91,98 and 111 among no BF, BF 1-4 $\mathrm{m}$ and $\mathrm{BF}>4$ $\mathrm{m}$ infants, respectively $(p<0.001)$.

\begin{tabular}{ll}
\hline Jadin et al. (2011) [15] & ExBF $<1 \mathrm{~m}, 1 \mathrm{~m}, \geq 2 \mathrm{~m}$ and \\
& exclusive standard caloric density \\
& formula (exFF20, $20 \mathrm{kcal}$ per \\
& ounce) and high caloric density \\
& formula (exFF22, 22 kcal per \\
& ounce)
\end{tabular}

Not evaluated ounce)
Mean number of infections during the first 3 years of life was: 5 among patients with $\mathrm{BF}>4 \mathrm{~m}, 7.5$ among those with BF $1-4 \mathrm{~m}$ and 8 in the no BF group $(p=0.015)$.

No significant differences in number of hospitalizations during the first 3 years of life.

Percentage of never colonized with P. aeruginosa through the first 2 years of age higher among infants with exBF $=1$ $\mathrm{m}(90 \%)$ as compared to exBF $<1 \mathrm{~m}$ (44\%), exBF $\geq 2 \mathrm{~m}(40 \%)$, exFF20 $(43 \%)$ and exFF22 (50\%).

Percentage of patients who had $\geq 2 \mathrm{P}$. aeruginosa infections through the first 2 years of age lower among exBF $=1 \mathrm{~m}(0)$ and exBF $\geq 2 \mathrm{~m}(0)$ as compared to $\mathrm{BF}<$ $1 \mathrm{~m}(13 \%)$, exFF20 (32\%) and exFF22 $(43 \%)(p=0.026$ for all group comparison and $p=0.003$ for BF vs. all FF infants).

Mean values of Wisconsin CXR scores at the age of 2 year lower among exBF $=1$ $\mathrm{m}$ (2.0) as compared to exBF $<1 \mathrm{~m}$ (4.5), exBF $\geq 2 \mathrm{~m}$ (5.7), exFF20 (3.4) and exFF22 (4.1) $(p=0.015)$.

No significant differences in S. aureus infections.

\begin{tabular}{|c|c|c|c|}
\hline Rosenfeld et al. (2012) [16] & BF in infancy vs. no BF & Not evaluated & $\begin{array}{l}\text { No significant association between BF } \\
\text { and P. aeruginosa acquisition (HR: 0.85, } \\
95 \% \text { CI: } 0.60-1.21 \text { ) }\end{array}$ \\
\hline Munck et al. (2018) [18] & $\begin{array}{l}\text { Different comparisons for } \\
\text { nutritional outcomes (exBF vs. } \\
\text { exFF during the first } 3 \mathrm{~m} \text { of life) } \\
\text { and pulmonary outcomes } \\
\text { (exclusively or partially BF for } 3 \\
\text { m vs. exFF) }\end{array}$ & Not evaluated & $\begin{array}{l}\text { No significant differences in } \mathrm{P} \text {. } \\
\text { aeruginosa acquisition ( } 37 \% \text { among exFF } \\
\text { infants and } 23 \% \text { among exclusively or } \\
\text { partially BF infants, } p=0.10 \text { ). } \\
\text { Initial acquisition of P. aeruginosa } a 1 \text { year } \\
(25 \% \text { among exFF infants and } 64 \% \\
\text { among exclusively or partial BF infants, } \\
p=0.06)\end{array}$ \\
\hline
\end{tabular}


Table 5. Cont.

\begin{tabular}{llll}
\hline $\begin{array}{l}\text { First Author (Year of } \\
\text { Publication) [Reference] }\end{array}$ & Comparisons & Respiratory Function & $\begin{array}{l}\text { Lung Infections and Other Pulmonary } \\
\text { Outcomes }\end{array}$ \\
\hline Fitzgerald et al. (2020) [21] & $\begin{array}{l}\text { BF of variable duration vs. never } \\
\text { BF }\end{array}$ & Not evaluated & $\begin{array}{l}\text { No significant association between BF } \\
\text { and hospitalization for pulmonary } \\
\text { exacerbation in the first } 36 \text { m of life (OR } \\
\text { adjusted for type of diagnosis, sex, } \\
\text { sibling with CF, parent smoking, private } \\
\text { health insurance and genotype: 1.85, } \\
95 \% \text { CI: 0.84-4.07.) }\end{array}$ \\
\hline Padoan et al. (2019) [19] & BF of variable duration vs. never & Not evaluated & $\begin{array}{l}\text { The risk of negative outcome as defined } \\
\text { by chronic P. aeruginosa infection and/or } \\
\text { faltering growth at 1 year of age was } \\
\text { higher among never as compared to BF } \\
\text { infants (OR 2.92, } p=0.061)\end{array}$ \\
\hline
\end{tabular}

BF: breastfed; CF: cystic fibrosis; CI: confidence intervals; CXR: Chest X ray; exBF: exclusively breastfed; exFF: exclusively formula fed; exFF20: exclusive standard caloric density formula (20 kcal per ounce); exFF22: exclusive high caloric density formula (22 kcal per ounce); FEV1: forced expiratory volume in one second; FVC: forced vital capacity; NBS: newborn screening; OR: odds ratio.

All studies evaluated the association between BF and lung infections, while only two studies also considered respiratory function indicators [13,14], one of which showed a positive association [14]. Colombo et al. reported a lower number of infections over the first three years of life among infants who had been breastfed for more than four months as compared to those who had been formula-fed or breastfed for a shorter period [14]. Parker et al. found lower IV antibiotic use over two years before the enrollment in their survey in patients who had been exclusively breastfed for more than six months as compared to formula-fed patients [13]. Among the three studies investigating P. aeruginosa acquisition or colonization $[15,16,18]$, one study found an inverse association [15], and two studies found null associations $[16,18]$, although one of them [18] reported a trend toward a later acquisition among exclusively or partially breastfed infants.

However, only one study evaluated the association between BF and a radiological score, showing higher scores among infants who had been breastfed for at least 2 months as compared to those breastfed for a shorter period [15].

One study on CF patients with MI evaluated a composite outcome including P. aeruginosa infection and faltering growth, reporting a higher risk of negative outcome among infants who were never breastfed as compared to breastfed infants, but the result was not statistically significant [19].

\section{Discussion}

The studies identified for the present systematic review are consistent in reporting a lower prevalence of BF among infants with CF than among healthy infants. Based on these studies, the impact of BF on anthropometric and pulmonary outcomes remains uncertain because data are based on relatively small studies that are largely heterogeneous in terms of design and findings.

BF prevalence is much lower than that reported in healthy infants, and it is initiated on average in $50 \%$ of newborn infants with CF. Data on BF duration are even scarcer, but seem to indicate that it is also shorter, particularly in patients with PI and MI.

The decision of mothers to discontinue $\mathrm{BF}$ is based on several factors, including personal perceptions of the adequacy of breast milk (BM), poor social and family support, and difficulties for women in reconciling work with child's care [22]. All these barriers play a more important role for mothers of children with $\mathrm{CF}$, who have to face many challenges soon after diagnosis, including the psychological stress associated with the newly diagnosed disease, the frequent failure to thrive of their infants and the multiple therapies prescribed to prevent the progression of the disease [12]. Moreover, the management of CF therapy in breastfed children requires further arrangements to ensure proper PERT and adequate supplementations of sodium, iron and vitamins; this may lead both the parents and the physician to decide on the early discontinuation of BF. Notably, iron supplementa- 
tion can paradoxically limit the highly efficient iron absorption from BM, by "blocking" lactoferrin [23-25].

On the other hand, initiatives to promote and support BF among mothers of children with CF have recently shown promising results in reducing the discontinuation of $B F$. In a recent study by Miller et al. [12], an International Board-Certified Lactation Consultant (IBCLC) was incorporated into the initial CF-diagnosis visit in order to support mothers who were already BF. After the intervention, $94 \%$ of mothers (16 out of 17 mothers) continued BF vs. $57 \%$ of the pre-intervention group (8 out of 14 mothers). Duration of BF and exclusive BF was increased, although not significantly, to an average of 7.7 and 4.5 months, respectively, compared to the 6.4 and 3.6 months in the pre-intervention group.

With regard to the relationship among BF, anthropometric and pulmonary outcomes, the available data are limited, based on a relatively small number of patients, and heterogeneous in terms of measured outcomes, comparisons and results. Overall, the results on anthropometric outcomes are controversial, while there is some evidence that BF may reduce or delay lung infections in CF.

Most studies did not find significant differences in anthropometric outcomes across different feeding modalities. Nevertheless, two studies suggested some benefits of BF for patients with MI, possibly impacting the later expression of the individual growth potential $[19,20]$. Accordingly, one study documented a positive association between BF and growth rate in 16 infants [20] and the other, based on 85 patients, reported a reduced risk of faltering growth and/or chronic P. aeruginosa infection at 1 year of age (evaluated as a composite outcome) among breastfed compared to never breastfed infants with CF [19]. It is well known that human milk contains high concentrations of antimicrobial proteins, including lactoferrin, lysozyme, lactadherin and HMO, and growth factors, such as transforming growth factor beta, epidermal growth factor and insulin-like growth factor, which may improve the gut microbiome in these patients [26].

Since only a few relatively small studies suggest a potential benefit of BF in reducing lung infections, the relationship between BF and pulmonary outcomes remains unclear. Most studies did not consider potential confounding variables (e.g., higher socio-economic status and maternal level of education in the BF group), and the majority had a retrospective design with possible recall bias.

When interpreting the results of the studies reported in this systematic review, some important issues related to the different periods in which they were carried out should be considered. First, the aggressive market campaigns in the 1970s and 1980s strongly influenced maternal feeding choices, and at that time, formula feeding was more frequent than in recent years. Second, the composition of formula milk has been improved over time to mimic BM, both in terms of nutritional and functional effects. Finally, the small amount of included studies, the short follow-up for some of them, and the high heterogeneity in the timing of the measurements, comparisons and outcomes should also be considered. This last issue prevented us from providing a quantitative summary measure of the association between $\mathrm{BF}$ and $\mathrm{CF}$ outcomes through a meta-analysis.

\section{Conclusions}

In conclusion, our systematic review indicates that $\mathrm{BF}$ can be recommended in $\mathrm{CF}$, since infants who are breastfed even for a prolonged period of time do not show a compromised growth, provided that they are monitored in specialized centers according to the Standards of Care [27]. MI does not seem to represent a contraindication to BF, even if only a few small studies considered the effect of BF in this subgroup of infants, who are at increased risk of growth faltering.

Large randomized clinical trials evaluating interventions of BF promotion with welldefined feeding strategies are needed to draw definitive conclusions on the positive effects of BF on CF outcomes. 
Author Contributions: Conceptualization, C.C., M.L.G. and G.A.; methodology, G.A.; writingoriginal draft preparation, C.C., M.L.G., G.A. and A.C.; writing-review and editing, C.C., G.A., V.D., A.C., F.M., C.A., M.L.G.; supervision, C.C. All authors have read and agreed to the published version of the manuscript.

Funding: This research received no external funding.

Institutional Review Board Statement: Not applicable.

Informed Consent Statement: Not applicable.

Data Availability Statement: Not applicable.

Conflicts of Interest: The authors declare no conflict of interest.

\section{References}

1. Bell, S.C.; Mall, M.A.; Gutierrez, H.; Macek, M.; Madge, S.; Davies, J.C.; Burgel, P.R.; Tullis, E.; Castaños, C.; Castellani, C.; et al. The future of cystic fibrosis care: A global perspective. Lancet Respir. Med. 2020, 8, 65-124. [CrossRef]

2. Lee, P.A. Hypoproteinemia and anemia in infants with cystic fibrosis. A presenting symptom complex often misdiagnosed. JAMA J. Am. Med. Assoc. 1974, 228, 585-588. [CrossRef]

3. Sokol, R.J.; Reardon, M.C.; Accurso, F.J.; Stall, C.; Narkewicz, M.; Abman, S.H.; Hammond, K.B. Fat-soluble-vitamin status during the first year of life in infants with cystic fibrosis identified by screening of newborns. Am. J. Clin. Nutr. 1989, 50, $1064-1071$. [CrossRef]

4. Borowitz, D.; Baker, R.D.; Stallings, V.; Bachrach, L.K.; Beall, R.J.; Ph, D.; Campbell, P.W.; Casey, S.C.; Cohen, M.B.; Corey, M.; et al. Consensus report on nutrition for pediatric patients with cystic fibrosis. J. Pediatr. Gastroenterol. Nutr. 2002, 35, 246-259. [CrossRef] [PubMed]

5. Turck, D.; Braegger, C.P.; Colombo, C.; Declercq, D.; Morton, A.; Pancheva, R.; Robberecht, E.; Stern, M.; Strandvik, B.; Wolfe, S.; et al. ESPEN-ESPGHAN-ECFS guidelines on nutrition care for infants, children, and adults with cystic fibrosis. Clin. Nutr. 2016, 35, 557-577. [CrossRef]

6. WHO. Exclusive Breastfeeding for Six Months Best for Babies Everywhere. Available online: http://www.who.int/mediacentre/ news/statements/2011/breastfeeding_20110115/en/ (accessed on 27 January 2021).

7. Ouzzani, M.; Hammady, H.; Fedorowicz, Z.; Elmagarmid, A. Rayyan-a web and mobile app for systematic reviews. Syst. Rev. 2016, 5. [CrossRef] [PubMed]

8. Wells, G.A.; Shea, B.; O'connell, D.; Petersen, J.; Welch, V.; Losos, M.; Tugwell, P. The Newcastle-Ottawa Scale (NOS) for Assessing the Quality of Nonrandomized Studies in Meta-Analyses; Department of Epidemiology and Community Medicine, University of Ottawa: Ottawa, ON, Canada, 2012; Available online: http:/ / www.ohri.ca/programs/clinical_epidemiology/oxford.asp (accessed on 27 January 2021).

9. Moher, D.; Liberati, A.; Tetzlaff, J.; Altman, D.G.; Altman, D.; Antes, G.; Atkins, D.; Barbour, V.; Barrowman, N.; Berlin, J.A.; et al. Preferred reporting items for systematic reviews and meta-analyses: The PRISMA statement. PLoS Med. 2009, 339 , b2535. [CrossRef]

10. Smith, C. Supporting Optimal Growth in Infants with Chronic Conditions: How Are We Doing and What Can We Do? Breastfeed. Med. 2019, 14, S18-S19. [CrossRef]

11. Luder, E.; Kattan, M.; Tanzer-Torres, G.; Bonforte, R.J. Current Recommendations for Breast-feeding in Cystic Fibrosis Centers. Am. J. Dis. Child. 1990, 144, 1153-1156. [CrossRef]

12. Miller, T.; Antos, N.J.; Brock, L.A.; Wade, T.; Goday, P.S. Lactation Consultation Sustains Breast Milk Intake in Infants with Cystic Fibrosis. J. Pediatr. Gastroenterol. Nutr. 2019, 69, 358-362. [CrossRef]

13. Parker, E.M.; O'Sullivan, B.P.; Shea, J.C.; Regan, M.M.; Freedman, S.D. Survey of Breast-Feeding Practices and Outcomes in the Cystic Fibrosis Population. Pediatr. Pulmonol. 2004, 37, 362-367. [CrossRef] [PubMed]

14. Colombo, C.; Costantini, D.; Zazzeron, L.; Faelli, N.; Russo, M.C.; Ghisleni, D.; Gatelli, I.; Giovannini, M.; Riva, E.; Zetterström, R.; et al. Benefits of breastfeeding in cystic fibrosis: A single-centre follow-up survey. Acta Paediatr. 2007, 96, 1228-1232. [CrossRef]

15. Jadin, S.A.; Wu, G.S.; Zhang, Z.; Shoff, S.M.; Tippets, B.M.; Farrell, P.M.; Miller, T.; Rock, M.J.; Levy, H.; Lai, H.J. Growth and pulmonary outcomes during the first $2 \mathrm{y}$ of life of breastfed and formula-fed infants diagnosed with cystic fibrosis through the Wisconsin Routine Newborn Screening Program. Am. J. Clin. Nutr. 2011, 93, 1038-1047. [CrossRef]

16. Rosenfeld, M.; Emerson, J.; McNamara, S.; Thompson, V.; Ramsey, B.W.; Morgan, W.; Gibson, R.L. Risk factors for age at initial Pseudomonas acquisition in the cystic fibrosis epic observational cohort. J. Cyst. Fibros. 2012, 11, 446-453. [CrossRef] [PubMed]

17. Leung, D.H.; Heltshe, S.L.; Borowitz, D.; Gelfond, D.; Kloster, M.; Heubi, J.E.; Stalvey, M.; Ramsey, B.W.; Stecenko, A.; Schechter, M.; et al. Effects of diagnosis by newborn screening for cystic fibrosis on weight and length in the first year of life. JAMA Pediatr. 2017, 171, 546-554. [CrossRef] [PubMed]

18. Munck, A.; Boulkedid, R.; Weiss, L.; Foucaud, P.; Wizla-Derambure, N.; Reix, P.; Bremont, F.; Derelle, J.; Schroedt, J.; Alberti, C. Nutritional Status in the First 2 Years of Life in Cystic Fibrosis Diagnosed by Newborn Screening. J. Pediatr. Gastroenterol. Nutr. 2018, 67, 123-130. [CrossRef] 
19. Padoan, R.; Cirilli, N.; Falchetti, D.; Cesana, B.M. Risk factors for adverse outcome in infancy in meconium ileus cystic fibrosis infants: A multicentre Italian study. J. Cyst. Fibros. 2019, 18, 863-868. [CrossRef]

20. Holliday, K.E.; Allen, J.R.; Waters, D.L.; Gruca, M.A.; Thompson, S.M.; Gaskin, K.J. Growth of human milk-fed and formula-fed infants with cystic fibrosis. J. Pediatr. 1991, 118, 77-79. [CrossRef]

21. Fitzgerald, C.; Linnane, B.; George, S.; Ni Chroinin, M.; Mullane, D.; Herzig, M.; Greally, P.; Elnazir, B.; Healy, F.; Mc Nally, P.; et al. Neonatal screening programme for CF: Results from the Irish Comparative Outcomes Study (ICOS). Pediatr. Pulmonol. 2020, 55, 2323-2329. [CrossRef]

22. Brown, C.R.L.; Dodds, L.; Legge, A.; Bryanton, J.; Semenic, S. Factors influencing the reasons why mothers stop breastfeeding. Can. J. Public Health 2014, 105. [CrossRef]

23. Cerami, C. Iron Nutriture of the Fetus, Neonate, Infant, and Child. Ann. Nutr. Metab. 2017, 71, 8-14. [CrossRef] [PubMed]

24. Domellöf, M.; Lönnerdal, B.; Abrams, S.A.; Hernell, O. Iron absorption in breast-fed infants: Effects of age, iron status, iron supplements, and complementary foods. Am. J. Clin. Nutr. 2002, 76, 198-204. [CrossRef]

25. Lönnerdal, B. Excess iron intake as a factor in growth, infections, and development of infants and young children. Proc. Am. J. Clin. Nutr. 2017, 106, 1681S-1687S. [CrossRef] [PubMed]

26. Ballard, O.; Morrow, A.L. Human Milk Composition: Nutrients and Bioactive Factors. Pediatr. Clin. North Am. 2013, 60, 49-74. [CrossRef]

27. Castellani, C.; Duff, A.J.A.; Bell, S.C.; Heijerman, H.G.M.; Munck, A.; Ratjen, F.; Sermet-Gaudelus, I.; Southern, K.W.; Barben, J.; Flume, P.A.; et al. ECFS best practice guidelines: The 2018 revision. J. Cyst. Fibros. 2018, 17, 153-178. [CrossRef] [PubMed] 